
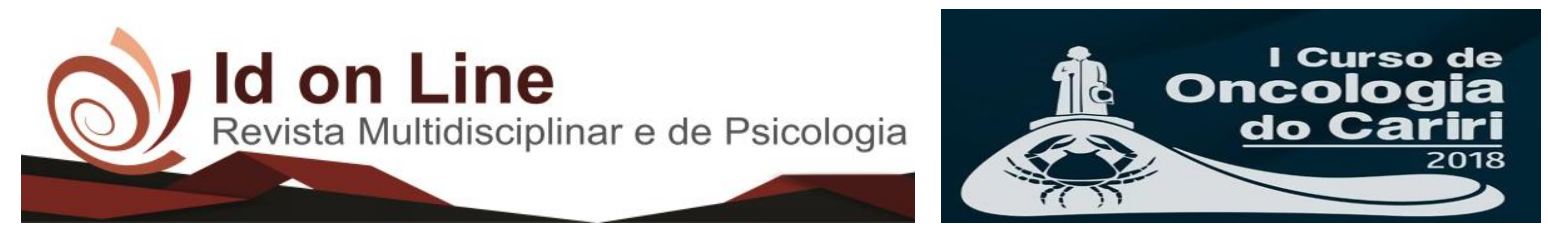

Resumo

\title{
LEUCEMIA DE CÉLULAS PLASMOCITÁRIAS COM NEUTROPENIA FEBRIL: UM RELATO DE CASO
}

Sheezara Teles Lira dos Santos ${ }^{1}$; Samia Israele Braz do Nascimento ${ }^{1}$; Maxsuel Rolim da Costa ${ }^{2}$

Introdução: A Leucemia de Células Plasmocitárias (LCP) é uma desordem linfoproliferativa rara - representa de 1 a $2 \%$ do total das neoplasias hematológicas-, caracterizada pela presença de plasmócitos absolutos de mais de $2 \times 10^{9}$ células ou mais de $20 \%$ de células plasmáticas no sangue periférico. Apresenta dois quadros: primária, leucemia no momento do diagnóstico, e secundária, consequência da transformação de um mieloma múltiplo conhecido. Acomete mais o sexo feminino, com prevalência entre 50 e 70 anos. Entre as manifestações clínicas, observam-se lesões líticas, fraturas patológicas, hepatoesplenomegalia, entre outros. É uma doença agressiva e com má resposta ao tratamento, com sobrevida média de 18 a 20 meses. A Neutropenia Febril é considerada uma emergência oncológica, representada pela ocorrência de febre em pacientes em tratamento quimioterápico com contagem de neutrófilos menor que 500/mm3. Objetivo: Relatar o caso de uma paciente portadora de Leucemia de Células Plasmocitárias que evoluiu com Neutropenia Febril. Descrição do caso: Trata-se de uma paciente, S.G. S., 59 anos, sexo feminino, admitida na Unidade de Terapia Intensiva (UTI), proveniente da Enfermaria Oncológica, onde estava internada há 7 dias com quadro de Febre e Dispneia e suspeita de Neutropenia Febril. É portadora de Leucemia de Células Plasmocitárias e estava no $1^{\circ}$ ciclo de Quimioterapia, sem outras comorbidades. Evoluiu com rebaixamento do nível consciência, quando foi intubada. Foram repostos 2 concentrados de hemácias, por queda do hematócrito, mas sem evidências de sangramento. Além disso, a paciente evoluiu com disfunção renal(Cr 2,3 mg\% e Ureia $161 \mathrm{mg} \%$ ) e distúrbios eletrolíticos (hipomagnesemia, hipocalcemia e hipofosfatemia). Realizou TC de Crânio que evidenciou espessamento mucoso em seio esfenoidal esquerdo. Fez uso de Cefepime, Bactrin, Metronidazol, Aciclovir profilático. Ficou por 15 dias na UTI, quando foi a óbito por parada cardiorrespiratória. Conclusão: A Leucemia de Células Plasmocitárias ainda continua sendo um grande desafio para a oncologia, sobretudo em casos de emergência como o caso descrito. Mesmo com o diagnóstico e tratamento precoce, o estado crítico da paciente pode interferir negativamente no desfecho final.

Palavras-chave: Leucemia de Células Plasmocitárias, neutropenia febril

\footnotetext{
${ }^{1}$ Acadêmica do $8^{\circ}$ semestre de Medicina da Faculdade de Medicina Estácio FMJ;

${ }^{2}$ Residente de Clínica Médica pela Estácio FMJ.

Autor correspondente: she.teles@hotmail.com
}

48 Id on Line Rev. Mult. Psic. V.12, N. 40. 2018 - ISSN 1981-1179 EDIÇÃO ESPECIAL: I CURSO DE ONCOLOGIA DO CARIRI / II JORNADA DE PESQUISA QUANTI-QUALITATIVA EM ONCOLOGIA. JUAZEIRO DO NORTE, 05 A 10 DE MARÇO DE 2018. Edição eletrônica em http://idonline.emnuvens.com.br/id 